\title{
Glargine and detemir: Safety and efficacy profiles of the long-acting basal insulin analogs
}

This article was published in the following Dove Press journal:

Drug, Healthcare and Patient Safety

26 October 2010

Number of times this article has been viewed

\author{
Kitty Poon \\ Allen B King \\ Diabetes Care Center, Salinas, CA, \\ USA
}

Correspondence: Allen B King

Diabetes Care Center, 1260 South

Main Street, Salinas, CA 93901, USA

Tel + I 83| 7699355

Fax + I 83| 7544955

Email Aking@diabetescarecenter.com

\begin{abstract}
Diabetes mellitus is a growing public health concern in the US and worldwide. Insulin therapy is the cornerstone of diabetes therapy, and the use of basal insulins will increase as clinicians strive to help their patients reach glycemic goals. Basal insulins have been continually improved upon over the years, and the long-acting basal insulin analogs, glargine and detemir, have many pharmacokinetic and pharmacodynamic advantages over neutral protamine Hagedorn insulin, namely, less variable absorption profiles, a less pronounced peak in effect, and a longer duration of action. Overall, glargine and detemir do not differ greatly in their safety and efficacy profiles. Major differences between the two include lower within-subject variability, lower risk of hypoglycemia, and a weight-sparing effect with insulin detemir. This review summarizes data from the key pharmacokinetic and pharmacodynamic studies, as well as clinical and observational studies to elucidate the role of each basal insulin analog in therapy.

Keywords: glargine, detemir, safety, hypoglycemia, weight, glucose variability
\end{abstract}

\section{Introduction}

Diabetes mellitus is a common, chronic illness. In the year 2000, the number of cases of diabetes in the US was 17.7 million. ${ }^{1}$ Worldwide, that number is at least 171 million. ${ }^{2}$ The number of people with diabetes continues to grow in epidemic proportions. The worldwide prevalence of diabetes is projected to increase to 366 million in $2030 .{ }^{1}$ Along with the prevalence of the disease, the global burden of diabetes continues to grow. Although the incidence of type 2 diabetes is increasing at younger ages, most of the people with diabetes in developed countries are older adults. ${ }^{2}$ However, in developing countries, diabetes affects mostly people aged $35-64$ years. ${ }^{2}$ This has serious implications in terms of the costs of loss in productivity. Due to its chronic nature, diabetes is a costly disease for the individual, health care systems, and society. Complications of diabetes cause 3.2 million deaths per year, and $2.5 \%-15 \%$ of annual health care budgets are used for diabetes-related care. ${ }^{2}$ As we rise to meet the challenges of the diabetes epidemic, prevention of complications through glycemic control in persons with diabetes is the goal, and safe and efficacious treatment will play a role in achieving that goal. This review focuses on insulin therapy, specifically on the safety and efficacy profiles of the long-acting basal insulin analogs, glargine and detemir, and the place of each in therapy.

\section{Glycemic control in patients with diabetes}

The underlying pathophysiology of diabetes mellitus is absolute or relative insulinopenia and, in the case of type 2 diabetes, there is insulin resistance as well. Large-scale landmark studies have demonstrated the benefits of insulin therapy. ${ }^{3-7}$ 
The Diabetes Control and Complications Trial (DCCT) showed that in type 1 diabetes mellitus, compared with conventional daily or twice-daily insulin therapy, intensive insulin therapy (at least three daily insulin injections or pump treatment) resulted in a significant decrease in microvascular complications, and any improvement in $\mathrm{HbA} 1 \mathrm{c}$ resulted in a decreased risk of complications. ${ }^{3}$ The follow-up observational Epidemiology of Diabetes Interventions and Complication (EDIC) study that was an extension of the DCCT also found that physiologic insulin replacement therapy decreased macrovascular risks in type 1 patients with diabetes mellitus and that the macrovascular benefits persisted from earlier physiologic insulin treatment, even when treatment was later equalized (a phenomenon known as "metabolic memory"). ${ }^{4}$ Benefits of insulin treatment are not limited to people with type 1 diabetes mellitus. The Kumamoto Study paralleled the DCCT and found a decreased incidence of microvascular complications (retinopathy and nephropathy) in insulinrequiring type 2 diabetes mellitus patients. ${ }^{5}$ The United Kingdom Prospective Diabetes Study (UKPDS) followed type 2 diabetes mellitus patients over 10 years and found that the intensive treatment group (sulfonylurea + insulin) fared better than the conventional group in regards to decreased microvascular disease. ${ }^{6}$ In a 10 -year post-trial follow-up of the UKPDS, there was a "legacy effect" of earlier glucose control, ie, a decrease in any diabetes-related endpoint, decreased microvascular disease, decreased myocardial infarction, and decreased all-cause mortality. ${ }^{7}$

The American Diabetes Association and the European Association for the Study of Diabetes, as well as the American Association of Clinical Endocrinologists/American College of Endocrinology have released statements on glycemic goals (see Table 1). ${ }^{8-10}$ Although the glycosylated hemoglobin $\left(\mathrm{HbA}_{1 \mathrm{c}}\right)$ goals differ, both guidelines advocate the early use of insulin. Insulin therapy is an effective means for achieving glycemic control and, as such, plays an important role in treatment.

\section{Long-acting basal insulin analogs}

Insulin exerts its actions through binding to the insulin receptor. It regulates glucose metabolism by promoting the synthesis and storage of glycogen, triglycerides, and

Table I Glycemic goals

\begin{tabular}{ll}
\hline American Diabetes Association and the & $\mathrm{HbA}_{\mathrm{Ic}}<7.0 \%$ \\
European Association for the Study of Diabetes & \\
American Association of Clinical Endocrinologists/ & $\mathrm{HbA}_{\mathrm{Ic}} \leq 6.5 \%$ \\
American College of Endocrinology & \\
\hline
\end{tabular}

protein in its major target tissues, ie, liver, fat, and muscle, and it inhibits hepatic glucose production. Long-acting basal insulin analogs (glargine and detemir) are the initial choice of insulin treatment in the US, and they are preferred over neutral protamine Hagedorn (NPH) insulin because of a longer duration of action, ${ }^{11}$ less pronounced peak in timeaction profiles, ${ }^{12}$ more consistent effects (less variability), ${ }^{12}$ and decreased risk of hypoglycemia. ${ }^{12}$ Glargine and detemir are the two long-acting basal insulin analogs currently available on the market.

\section{Molecular structures of glargine and detemir}

Basal insulin analogs were created to improve on the shortcomings of NPH (ie, pronounced peak, short duration of action, variable absorption rates) and to mimic better the normal physiologic basal insulin response.

Insulin glargine (Gly ${ }^{\mathrm{A} 21} \operatorname{Arg}^{\mathrm{B} 21} \mathrm{Arg}^{\mathrm{B} 32}$ human insulin) is synthesized via recombinant DNA technology using Escherichia coli K12. ${ }^{13}$ The amino acid asparagine at position A21 in human insulin is replaced with glycine, and two arginines are added to the $\mathrm{C}$-terminus of the $\beta$-chain (Figure 1a). ${ }^{13}$ These modifications cause a shift in the isoelectric point towards neutrality. At a $\mathrm{pH}$ of 4 in acidic solution, glargine is not soluble at physiologic neutral $\mathrm{pH}$ and forms a microprecipitate upon injection into subcutaneous tissue. ${ }^{13}$

Insulin detemir [Lys ${ }^{\mathrm{B} 29}$ (N-tetradecanoyl)des(B30)human insulin] is also synthesized via recombinant technology, using the yeast Saccharomyces cerevisiae. ${ }^{14}$ It differs from human insulin in that the amino acid threonine in position $\mathrm{B} 30$ is omitted and a carbon 14 fatty acid chain is attached to lysine at B29 (Figure 1b). ${ }^{14}$ Detemir has a pH of 7.4 and is therefore soluble at physiologic $\mathrm{pH} .{ }^{14}$ It is reversibly bound to albumin. ${ }^{14}$ Both glargine and detemir are clear solutions ${ }^{13,14}$ that unlike NPH do not require resuspension prior to injection.

\section{Pharmacokinetics}

Pharmacokinetics govern drug absorption, distribution, and elimination. The pharmacokinetic goals for basal insulin analogs are a steady rate of absorption, avoidance of peaks in plasma levels, and a predictable absorption profile. ${ }^{15}$

Glargine achieves a slower, more prolonged absorption profile through reduced solubility at physiologic $\mathrm{pH} .{ }^{16} \mathrm{Upon}$ injection into neutral $\mathrm{pH}$ subcutaneous tissue, glargine forms microprecipitates that dissolve slowly, delaying its absorption and thus prolonging its duration of action. ${ }^{16}$ 
A Insulin glargine

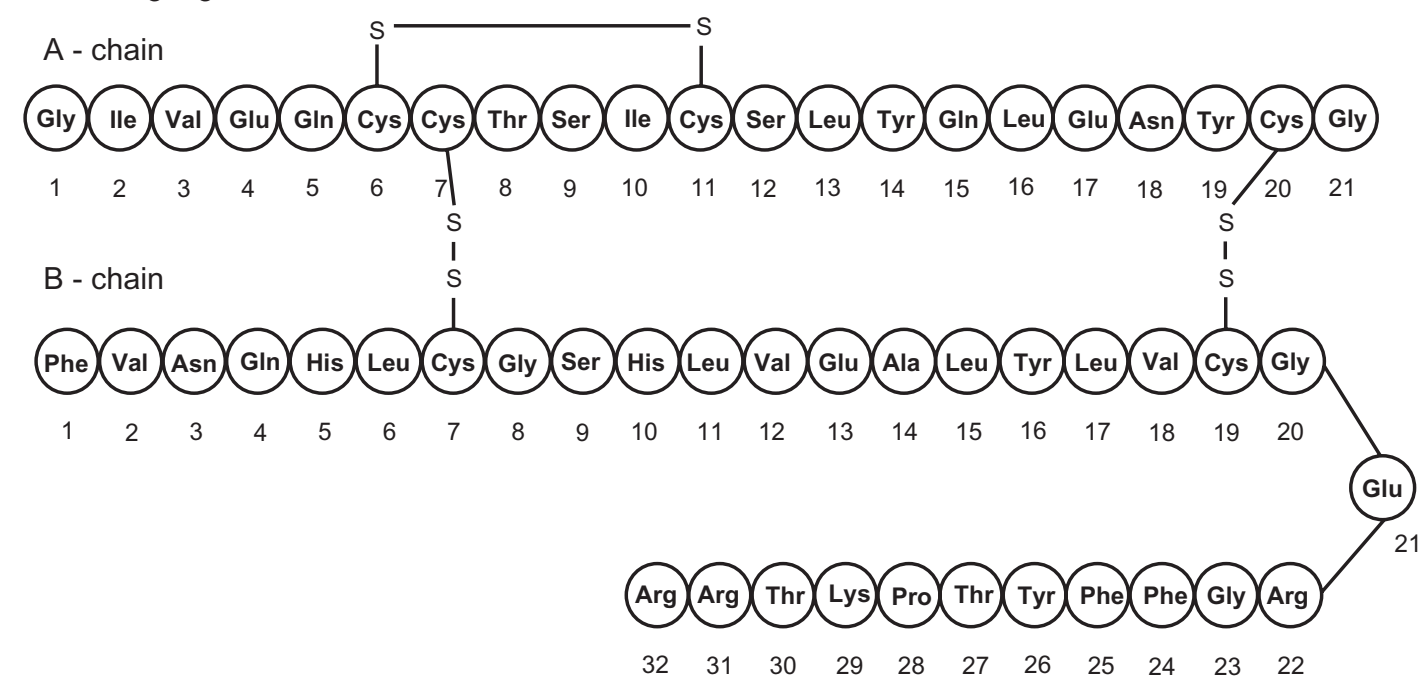

B Insulin detemir

LysB29 (N-tetradecanoyl) des (B30) human insulin

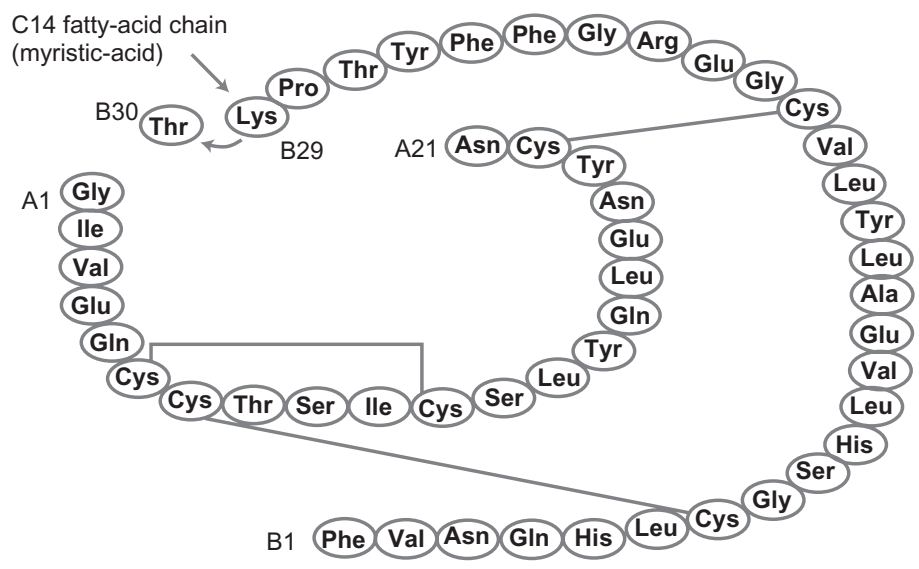

Figure I Molecular structures of insulin glargine and insulin detemir.

Owens et $\mathrm{al}^{17}$ investigated the subcutaneous absorption rates of radioactively-labeled insulin glargine of differing zinc contents $(15,30$, and $80 \mu \mathrm{g} / \mathrm{mL})$, in comparison with $\mathrm{NPH}$, by measuring the rates of disappearance of radioactivity. Glargine was absorbed more slowly and with a relatively peakless profile versus NPH, which demonstrated a pronounced peak of action. ${ }^{17}$ Compared with each other, solutions of glargine with higher zinc content demonstrated a slower absorption profile, which is consistent with the role of zinc in glargine absorption. ${ }^{17}$ In a second study, they also found no significant difference in absorption rates of glargine with $30 \mu \mathrm{g} / \mathrm{mL}$ zinc content (formulation used in Phase II and Phase III clinical trials) when injected in different subcutaneous injection sites (arm, leg, abdomen). ${ }^{17}$ The formulation of glargine that is currently on the market contains $30 \mu \mathrm{g} / \mathrm{mL}$ zinc. $^{13}$
In comparison with glargine, detemir retains solubility at physiologic $\mathrm{pH}$, and injection into the subcutaneous tissue forms a soluble depot. ${ }^{18}$ The acylation of detemir allows for reversible albumin binding, and along with its hexamerforming abilities (stabilizing self-association), results in prolonged action. ${ }^{18}$

Havelund et a $\mathrm{l}^{19}$ investigated the underlying mechanism for the low variability in absorption of insulin detemir. Using size-exclusion chromatography and manipulation of the contents of the eluent to simulate changes at the injection depot, they modeled self-association and albumin affinity of detemir and other insulin analogs in pigs at the injection depot, the depot-interstitial junction, and in plasma. The data suggest that one mechanism by which absorption of detemir after subcutaneous injection is protracted is via self-association into dihexamers, presumably through 
interactions between the fatty acid chains. ${ }^{19}$ Hexameric detemir reaches a hexamer-dihexamer equilibrium after injection in subcutaneous tissue, because preservatives such as phenol, cresol, and polyol in the pharmaceutical formulation diffuse across the endothelial membranes and sodium chloride enters the subcutaneous injection depot. ${ }^{19}$ At the depot-interstitial junction, detemir comes into contact with and binds to albumin; all forms of insulin detemir (monomeric, hexameric, and dihexameric) will bind to albumin. ${ }^{19}$ In comparison with the acylated insulin analogs, those with more stable self-association states have slower disappearance rates $\left(T_{1 / 2}\right)$, ie, 10.2 hours for detemir versus 8.8 hours for acylated stable hexamer, 6.9 hours for an acylated weakly associating hexamer, and 2.9 hours for an acylated monomer. ${ }^{19}$ This suggests that self-association is an important property in the absorption rate of detemir. However, the stable nonalbumin-binding hexamer Co (III) insulin had an elimination half-life of only 2.8 hours. This suggests that not only does the extent of self-association influence the absorption rate of the insulin analog, but albumin binding also appears to play a role in delaying absorption. The proposed mechanism of action is that self-association of detemir increases retention in the injection depot, slowing absorption and increasing albumin-binding opportunities, and albumin binding in the depot further delays absorption.

In a compartmental (plasma and interstitial fluid) modeling study, Dea et $\mathrm{al}^{20}$ infused equimolar amounts of an acylated insulin analog NN304 [Lys ${ }^{\mathrm{B} 29}$ (tetradecanoyl) des (B30) human insulin] or human insulin in dogs under euglycemic clamp conditions to determine how albumin binding affected NN304 action, ie, whether it was due only to its unbound (and presumably active) fraction. Dea et $\mathrm{a}^{20}$ found that elimination and transendothelial transport of NN302 to interstitial fluid was reduced, compared with human insulin, although not to the degree expected for an albumin-binding insulin analog. However, there was no reduction in action (glucose uptake) of NN304 versus human insulin once it was in the interstitial fluid, despite high concentrations of albumin and predicted albumin binding. ${ }^{20}$ This suggests that the albumin-binding property of NN304 blunts plasma kinetics (hepatic elimination and transendothelial transport), as compared with human insulin, thus delaying entrance into the interstitial fluid, but it does not blunt the kinetics or efficacy in interstitial fluid which is the compartment of action.

Albumin binding may also have buffering effects against variable absorption. Because detemir is $98 \%$ albumin-bound in the circulation, variations in blood flow rate at the injection site do not affect absorption rates to as great an extent. ${ }^{18}$ Absorption normally depends on movement across capillary membranes governed by a concentration gradient and on the capillary flow rate. A high flow rate will decrease capillary concentration and increase absorption from the interstitium, while a low flow rate will increase capillary concentration and decrease absorption of insulin from the interstitial fluid. ${ }^{18}$ Insulin detemir is almost completely albumin-bound once it is injected into the subcutaneous tissue, and albuminbound detemir forms rather large complexes that do not easily traverse capillary membranes. ${ }^{18}$ Therefore, the free detemir concentration is relatively constant and independent of flow rate, which may explain decreased variability in absorption.

\section{Pharmacodynamics}

Pharmacodynamics relate to the pharmacologic effect of a drug, ie, the clinical response. The pharmacodynamic goals of basal insulin analogs are protracted action ${ }^{15}$ and potency (dose-response). Isoglycemic clamp studies are considered the gold standard for pharmacodynamic research. ${ }^{21}$ However, the methodology of glucose clamp studies may vary considerably, making comparisons between studies difficult.

Insulin glargine has a relatively constant concentration/ time action profile and long duration of action. According to the manufacturer's package insert ${ }^{13}$ for Lantus ${ }^{\circledR}$ (sanofiaventis, Paris, France), the median duration of action was 24 hours with a range of 10.8 to $>24$ hours.

In a double-blind, randomized, two-way crossover, euglycemic clamp study ${ }^{22}$ comparing the time-action profiles of HOE 901 (insulin glargine) and NPH in subjects with type 1 diabetes, the onset of action was slower with glargine (1.11 hours versus 0.71 hours), but the median duration of action of glargine was significantly longer than NPH (22.8 hours versus 13.8 hours). Glargine was also found to have a flatter, consistent glucose infusion rate (GIR)-time profile compared with $\mathrm{NPH} .{ }^{22}$

Heinemann et $\mathrm{a}^{16}$ also conducted a randomized, doubleblind, placebo-controlled, three-way, crossover euglycemic glucose clamp study to determine the pharmacodynamic properties of injecting $0.4 \mathrm{U} / \mathrm{kg}$ body weight insulin glargine compared with $0.4 \mathrm{U} / \mathrm{kg} \mathrm{NPH}$. The metabolic activity of glargine reached a plateau within four hours after subcutaneous injection, whereas NPH showed a peak at 4-6 hours. ${ }^{16}$ With time, metabolic activity declined with both insulins, but the duration of action of glargine was at least 30 hours in this study. However, this was a single-injection study, and steady state was not established. 
Porcellati et $\mathrm{a}^{23}$ conducted a randomized, double-blind, crossover euglycemic glucose clamp study comparing the pharmacokinetics and pharmacodynamics of glargine and detemir at steady state in type 1 diabetes patients. They used a dose of $0.35 \mathrm{U} / \mathrm{kg}$ body weight for both glargine and detemir, and found a decreased GIR and GIR area under the curve with detemir after 12 hours, but not with glargine, and decreased lipolytic activity of detemir compared with glargine. Based on their findings, Porcellati et al suggested that glargine be used as a once-daily basal insulin for people with type 1 diabetes, while detemir requires twice-daily use. These results differ from other glucose clamp studies (albeit of different designs) that have demonstrated a similar duration of action for glargine and detemir.

Heise et $\mathrm{al}^{12}$ conducted a randomized, double-blind euglycemic glucose clamp study to compare within-subject variability in the glucose-lowering effect of detemir, NPH, and glargine in type 1 diabetes. In comparison with the Porcellati study, Heise et a ${ }^{12}$ used a larger dose of detemir $(0.4 \mathrm{U} / \mathrm{kg}$ versus $0.35 \mathrm{U} / \mathrm{kg}$ ), and they used the Biostator instead of the manual clamp technique. In this study, they demonstrated a more predictable glucose-lowering effect with detemir. Within-subject variability for GIR area under the curve (0-12 hours) and over 24 hours was lower for detemir versus both NPH and glargine. Also, within-subject variability was lower for detemir. The authors hypothesized that the differences in variability seen with detemir versus NPH and glargine may be due to their differing mechanisms of protraction after subcutaneous injection. Incomplete resuspension of NPH, and in the case of glargine, necessity for precipitation and dissolution in the subcutaneous tissue may be sources of variation. The duration of action of detemir in this study was a median of 23.0 hours (range 15.4-24 hours) and 24.0 hours (range 18.7-24 hours) for glargine. ${ }^{12}$

Plank et a ${ }^{24}$ also found a dose-dependent duration of action for insulin detemir in type 1 diabetes from 5.2 hours at the lowest dose of $0.1 \mathrm{U} / \mathrm{kg}$ to 23.2 hours at the highest dose of $1.6 \mathrm{U} / \mathrm{kg}$ and a flat and protracted pharmacodynamic profile (Figure 2). Limitations of this study include it being a first-dose study and not a steady-state study.

In people with type 2 diabetes, Klein et a ${ }^{25}$ compared the time action profiles of detemir, NN304 (another albuminbound basal analog), and glargine. They found that the duration of action was dose-dependent with both glargine and detemir. At low and medium doses $(0.4 \mathrm{U} / \mathrm{kg}, 0.8 \mathrm{U} / \mathrm{kg})$, the duration of action was below 24 hours. Because the duration of action of glargine and detemir were comparable in this study, the authors asserted that insulin detemir is just as appropriate for once-daily dosing as insulin glargine in type 2 diabetes patients. Within-subject variability was lower with detemir versus glargine and there was no significant difference in between-subject variability. No major differences were found in shape of metabolic profiles (GIR) and duration of action or effect on endogenous glucose production, peripheral glucose uptake, and free fatty acids between detemir and glargine (at doses of $0.4-0.8 \mathrm{U} / \mathrm{kg}$ ). None of the three insulins tested showed a peakless profile, with equal distribution of metabolic effect over 24 hours.

In an attempt to consolidate the information from the different isoglycemic clamp studies comparing glargine

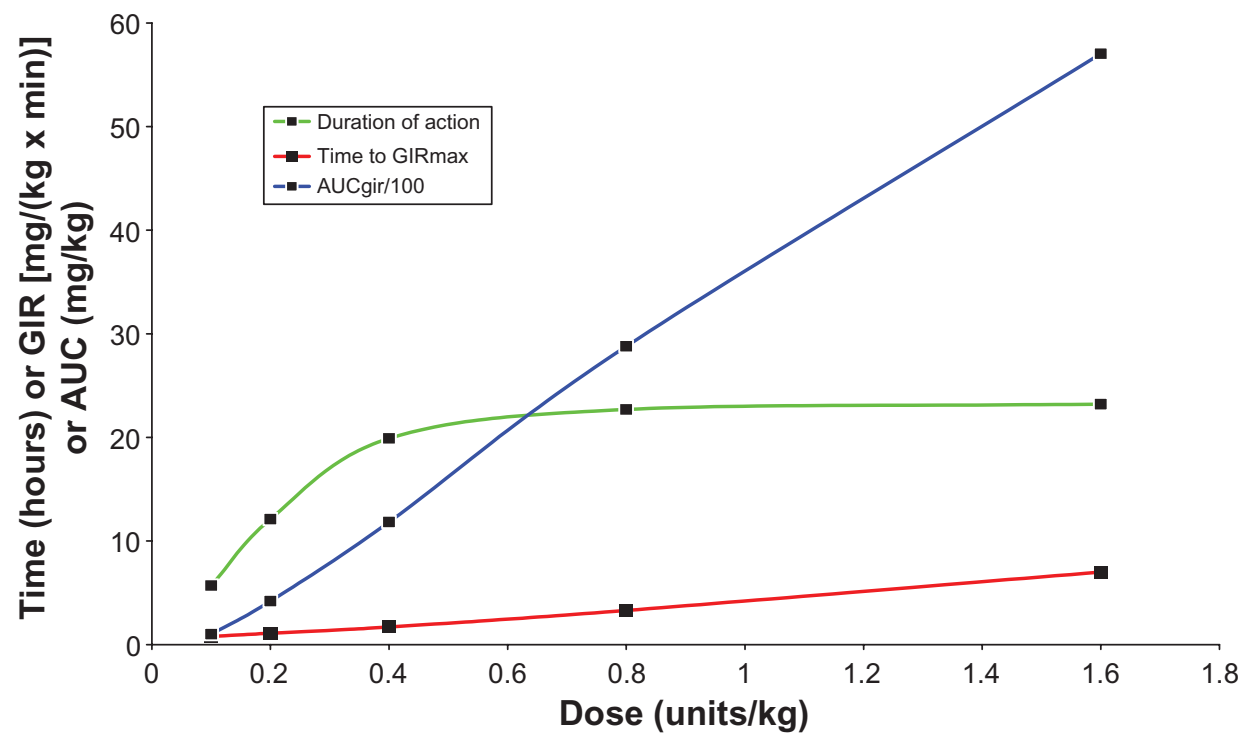

Figure 2 Pharmacodynamic profile of insulin detemir.

Duration of action, time to peak action $\left(\mathrm{GIR}_{\max }\right)$, and overall effect $\left(\mathrm{AUC}_{\mathrm{GIR}} / / 00\right)$. Data obtained from Plank et al. ${ }^{20}$ 
and detemir, Heise and Pieber ${ }^{21}$ reviewed the areas of major contention, including the mean shape of their pharmacodynamic profile (ie, "flatness" of action, as measured by the shape of their GIR curves), duration of action, and variability of the two insulins. They reviewed 10 studies (five with subjects having type 1 diabetes, two with type 2 diabetes subjects, and three with healthy subjects) and found that results of the studies were fairly consistent, despite methodologic differences. Both detemir and glargine exhibit overall flatter pharmacodynamic profiles than NPH, but a small peak occurs for both in the form of a "gentle rise and fall" in effect over 24 hours. ${ }^{21}$ The duration of action (close to 24 hours) was found to be similar between glargine and detemir at clinically relevant doses of $0.35-0.8 \mathrm{U} / \mathrm{kg}$. ${ }^{21}$ The Porcellati et al study ${ }^{23}$ is the exception to this. In regards to variability, detemir demonstrates less within-subject variability in its effect. Neither insulin glargine nor insulin detemir perfectly mimics the physiologic, peakless profile of endogenous basal insulin.

\section{Comparison of effectiveness in glycemic control}

It is fairly well established that glargine and detemir have improved pharmacokinetic and pharmacodynamic profiles, as compared with NPH. This raises the questions of how do these two basal insulin analogs compare with NPH and with each other in terms of glycemic control? Many studies have compared glargine and detemir with NPH, but few studies have compared glargine and detemir head-to-head. This review focuses mainly on studies that compare glargine with detemir.

\section{Clinical trials with NPH}

Horvath et $\mathrm{al}^{26}$ conducted a meta-analysis comparing the efficacy of glargine and detemir with that of NPH in patients with type 2 diabetes. Glargine and detemir were almost identically effective, compared with NPH, in long-term metabolic control (as measured by $\mathrm{HbA}_{1 \mathrm{c}}$ ). There was no significant difference for severe hypoglycemia rates in any of the trials, but the rates of symptomatic hypoglycemia were lower with glargine, overall hypoglycemia was lower with detemir, and nocturnal hypoglycemia was lower with glargine and detemir, versus NPH. No evidence was obtained on the beneficial effect of glargine and detemir on patient-oriented outcomes, ie, mortality, morbidity, quality of life, or costs. Therefore, the authors could only conclude that there was a minor clinical benefit of long-acting insulin analogs for type 2 diabetes patients treated with basal insulin in regards to nocturnal hypoglycemia. Although the results of this study were disappointing, it is important to keep in mind that the methodologic quality of the studies used was rated low.

\section{Clinical trials with glargine and detemir}

Pieber et $\mathrm{al}^{27}$ compared glycemic control and risk of hypoglycemia in patients with type 1 diabetes randomized to either twice-daily insulin detemir or once-daily insulin glargine injections, in combination with premeal aspart to demonstrate noninferiority. The $\mathrm{HbA}_{1 \mathrm{c}}$ improvement was comparable in both groups, but the target of $7.0 \%$ was not reached in either study. Home-measured fasting blood glucose (BG) was lower with glargine. No significant difference was found between the overall within-subject variation in plasma glucose, but within-subject variation in pre-dinner plasma glucose was lower with detemir. This may be due to a waning effect of glargine (only once-daily injection allowed per US Food and Drug Administration guidelines) or a lower mean predinner BG for detemir (in some subjects, a morning detemir dose was added if predinner BG was not at goal). The difference in overall risk of hypoglycemia was not statistically significant, but the risk of severe and nocturnal hypoglycemia was lower with detemir (higher plasma glucose in early morning was seen with detemir). There was no significant difference in weight gain. The mean daily basal dose was higher with detemir compared with glargine ( 0.47 versus $0.35 \mathrm{U} / \mathrm{kg})$, but bolus insulin doses were lower in detemir group $(0.36$ versus $0.39 \mathrm{U} / \mathrm{kg}$ ). The total mean daily dose of insulin was $0.83 \mathrm{U} / \mathrm{kg}$ with detemir versus $0.74 \mathrm{U} / \mathrm{kg}$ with glargine, attributable to twice-daily dosing of detemir. In light of these results, the authors concluded that twice-daily detemir dosing is as effective as once-daily glargine when used in combination with premeal aspart in type 1 diabetic patients. Detemir also has the advantage of reduced risk of severe and nocturnal hypoglycemia, compared with glargine. ${ }^{27}$

Rosenstock et $\mathrm{al}^{28}$ conducted a parallel-group, headto-head comparison of detemir (once or twice daily) to glargine (once daily) as add-on treatment to oral antidiabetic agents for type 2 diabetes patients. They were able to demonstrate noninferiority for detemir at higher doses (mainly twice-daily dosing). The mean daily detemir dose was higher, ie, $0.78 \mathrm{U} / \mathrm{kg}(0.52 \mathrm{U} / \mathrm{kg}$ with once-daily dosing, $1.00 \mathrm{U} / \mathrm{kg}$ with twice-daily dosing) than the mean daily dose of glargine $(0.44 \mathrm{U} / \mathrm{kg})$. Less weight gain occurred with once-daily detemir $(3.0 \mathrm{~kg})$ versus glargine (3.9 kg). Within-participant variability for self-monitored fasting BG and predinner plasma glucose did not differ by treatment nor did relative risk of overall nocturnal hypoglycemia. 
Hollander et $\mathrm{al}^{29}$ compared once- or twice-daily insulin detemir with once-daily glargine in a basal-bolus regimen for type 2 diabetes patients. They found no difference between glargine and detemir in regards to mean $\mathrm{HbA}_{1 \mathrm{c}}$ or decrease in $\mathrm{HbA}_{1 \mathrm{c}}$ or in mean fasting $\mathrm{BG}$ or mean decrease in fasting $\mathrm{BG}$ from baseline. Interestingly, the decrease in $\mathrm{HbA}_{1 \mathrm{c}}$ was not significantly affected by whether detemir was administered as a once a day or twice a day injection, suggesting that adding a second dose of basal insulin for predinner BG may not offer a clinical advantage over once-daily dosing in type 2 diabetes patients. ${ }^{29}$ The doses of basal and prandial insulins were not significantly different between the two groups. There was also no significant difference between glargine and detemir in regards to hypoglycemia and adverse effects. Of note is that mean weight gain was lower with the detemir group, ie, $2.8 \mathrm{~kg}$ versus $3.8 \mathrm{~kg}$ in the glargine group.

Many clinical trials have used twice-daily detemir dosing in comparison with once-daily glargine, which makes comparison of the two basal insulins difficult. In a randomized, double-blind, crossover study using continuous glucose monitoring, King ${ }^{30}$ demonstrated that administration of oncedaily detemir in type 2 diabetes patients was equally effective in achieving glucose goals as once-daily glargine. The mean dosage used for the two basal insulins were not significantly different, with a mean dosage of $0.26 \mathrm{U} / \mathrm{kg}$.

The PREDICTIVE trials were multinational, prospective, observational studies examining the safety and efficacy of detemir in diabetic patients in real-life clinical practice. Those trials were uncontrolled and unblinded, but largescale. In these studies, insulin detemir was found to improve glycemic control (as measured by $\mathrm{HbA}_{1 \mathrm{c}}$ ) in both type 1 and type 2 diabetic patients, while causing less hypoglycemia and less weight gain (weight neutral). ${ }^{31}$ In other PREDICTIVE studies, ${ }^{32-34}$ type 2 diabetes patients treated with basal insulin in combination with oral antidiabetic drugs who switched to detemir from NPH or glargine achieved a mean $\mathrm{HbA}_{1 \mathrm{C}}$ reduction of up to $0.6 \%$, reductions in total and nocturnal hypoglycemia, and also weight loss.

\section{Short and long-term safety and tolerability profiles Hypoglycemia}

Hypoglycemia is a major barrier and limiting factor in the glycemic management of patients with diabetes. Because of it, the goal of euglycemia remains elusive. Under normal physiologic conditions, the body has evolved mechanisms that prevent wide fluctuations in glucose levels. Hypoglycemia is an iatrogenic clinical event that occurs in people who use drugs, such as insulin and insulin secretogues, that raises circulating exogenous or endogenous insulin levels and lowers the plasma glucose concentration. ${ }^{35}$ In individuals with type 1 diabetes, hypoglycemia is quite common, in that blood glucose levels may be below $2.8 \mathrm{mmol} / \mathrm{L}$ $(<50 \mathrm{mg} / \mathrm{dL})$ up to $10 \%$ of the time and, on average, a patient will experience two symptomatic hypoglycemic episodes per week and one episode per year of severe temporarily incapacitating hypoglycemia that may include seizure or coma. ${ }^{35}$ Although hypoglycemia is less frequent in people with type 2 diabetes, it becomes more of a factor later in the course of the disease with progressive beta cell failure, and increases with duration of insulin therapy until the risk approaches that in type 1 diabetes. ${ }^{35}$ The impact of hypoglycemia in terms of morbidity include unpleasant physical symptoms, potential cognitive impairment in children, and fear and anxiety over hypoglycemia itself, and a mechanism of mortality may be cardiac arrhythmia. ${ }^{35}$ Because patients are more likely to remember severe hypoglycemic episodes, and because severe hypoglycemic episodes by nature pose a greater risk, estimates of the incidence of those episodes are the most reliable, although they only represent a small number of total hypoglycemic episodes. ${ }^{35}$ When data on hypoglycemia incidence are obtained from clinical trials, one has to take into account that most of the time, hypoglycemia is not a primary outcome and the manner in which the data were collected varies, with prospective data collection being more reliable than that from retrospective studies. ${ }^{35}$

In a treat-to-target trial, Riddle et $\mathrm{al}^{36}$ randomized type 2 diabetic subjects who were already on oral therapy to either glargine or NPH for further glycemic control to an $\mathrm{HbA}_{1 \mathrm{c}}$ goal of $<7.0 \%$. Hypoglycemia was one of the primary outcome measures. At the end of the study, mean fasting BG values and $\mathrm{HbA}_{1 \mathrm{c}}$ were comparable between the two groups, but the rates of nocturnal hypoglycemia and other symptomatic hypoglycemia was lower with glargine. So, compared with $\mathrm{NPH}$, the addition of glargine to oral diabetic medications can help type 2 diabetics achieve an $\mathrm{HbA}_{1 \mathrm{c}}$ goal of $<7.0 \%$, without increased risk of hypoglycemia.

The Pieber et al study ${ }^{27}$ and the PREDICTIVE ${ }^{\circledR}$ studies $^{31-34}$ demonstrated less hypoglycemia with detemir compared with both glargine and NPH.

Hypoglycemia and fear of hypoglycemia may affect adherence to treatment and be a barrier to euglycemia. Because of their pharmacokinetic and pharmacodynamic profiles, basal insulin analogs, glargine and especially detemir, are less likely than NPH to cause hypoglycemia. This allows for insulin doses to be titrated upward closer to 
goal without increased hypoglycemia and its accompanying morbidity and mortality.

\section{Allergic and injection site reactions}

Rosenstock et al ${ }^{28}$ found more frequent injection site reactions with detemir compared with glargine $(4.5 \%$ versus $1.4 \%$, respectively). There was a higher withdrawal rate of subjects in the detemir group ( $21 \%$ versus $13 \%$ ), partly due to adverse effects ( $8 \%$ versus $4 \%)$ such as injection site reactions.

\section{Drug-drug interactions}

The reversible albumin-binding properties of detemir raise the concern of potential competitive albumin binding of other compounds in the serum. This risk is minimized, because the molar serum concentration of insulin detemir is 1:50,000 of albumin at therapeutic doses. ${ }^{18}$ That and the numerous fatty acid binding sites (eight sites) on each albumin molecule make it unlikely that detemir will occupy binding sites to a significant extent. ${ }^{18}$ In vitro studies have shown that even at a detemir:albumin concentration of 1:1, detemir did not interact or interfere with drugs such as phenylbutazone, warfarin, ibuprofen, diazepam, tolbutamide, glibenclamide, aspirin, or valproate. ${ }^{18}$

\section{Mitogenicity potential of insulin analogs}

Novel insulin analogs provide many benefits of improved glycemic control, but these benefits must not be achieved at the cost of increased safety risks for long-term users. In the early stages of insulin analog development, it was found that a single substitution in the amino acid sequence of the insulin molecule into B10 Aspart led to increased mitogenic activity in rodents. ${ }^{37}$ The mechanism behind the increased mitogenic activity is not clear, but B10 Aspart had an increased insulin-like growth factor 1 receptor to insulin receptor affinity ratio and an increased receptor binding time. ${ }^{37}$ The lesson learned from B10 Aspart is that it is important to test fully the toxicopharmacologic effects of insulin analogs.

The safety profile of the basal insulin analogs at the receptor/cell level was determined using measurements of receptor affinities by Kurtzhals et al. ${ }^{37}$ The insulin receptor (IR) affinity of glargine is similar to that of human insulin, while detemir has a lower IR affinity. Human insulin receptor (h-IR) binding and human insulin-like growth factor receptor (hIGF-IR) binding of detemir was less potent than human insulin, with hIGF-IR binding even less potent than that of $\mathrm{h}$-IR binding, and the IR residence time was not increased. ${ }^{37}$
Insulin detemir did not exhibit an increased mitogenic potency. ${ }^{37}$ Insulin glargine had a 6.5 time greater potency in binding to the IGF-I receptor and greater mitogenic potency than human insulin, due to the B31B32diArg substitution which provides glargine with a greater affinity for the IGF-I receptor. ${ }^{37}$ But the receptor residence time of glargine was not different from that of human insulin. These findings are greater than previously reported. The clinical safety implications of these findings are not clear, but in comparison with glargine, insulin detemir, because of its lower hIGF-R binding potency and lower mitogenic potency, does not appear to cause safety concerns.

A recent German observational, retrospective study published by Hemkins et al raised the concern of an increased risk of malignancies with human insulin and glargine. ${ }^{38}$ However, this study is fraught with methodologic shortcomings and limitations..$^{38}$ For example, given the short exposure time to insulin glargine (1.31 years), it is unlikely that glargine caused cancer in the patients studied, and the observational groups lacked important controls. ${ }^{38}$ Ehninger and Schmidt ${ }^{39}$ argued in their commentary on the Hemkins et al study that the observational data leading to the suggestion of increased risk of malignancies with insulin glargine are not founded on methodologically and statistically sound analyses, and that more sound scientific evidence is needed before conclusions such as those are made.

A consensus statement released by experts from the American Diabetes Association and the American Cancer Society ${ }^{40}$ addressed the increased risk of certain types of malignancies of the liver, pancreas, endometrium, and, to a lesser extent, the colon and rectum, breast, and bladder, in people with diabetes. The report acknowledged that although persons with diabetes who use exogenous insulin appeared to be at increased risk, the data on possible associations of insulin analogs to cancer (and glargine as compared with other analogs) are limited and inconclusive.

\section{Pregnancy}

Both glargine and detemir are rated by the Food and Drug Administration as Pregnancy category C drugs. Detemir has not been studied in pregnancy. Recently, Pollex et al ${ }^{41}$ studied the use of glargine during pregnancy in a transplacental ex vivo human placental lobule perfusion study. Their results suggest that at therapeutic levels $(150 \mathrm{pmol} / \mathrm{L}=20 \mu \mathrm{U} / \mathrm{mL}$, which is the therapeutic level achieved after subcutaneous injection of a single dose of $0.3 \mathrm{U} / \mathrm{kg}$ ), insulin glargine does not cross the placenta in measurable amounts. ${ }^{41}$ It also appears that the placenta may be able to sequester or metabolize very 
high concentrations of insulin glargine. ${ }^{41}$ At this time, neither glargine nor detemir are approved for use in pregnancy. More studies are needed to investigate the safety of basal insulin analogs in pregnancy.

\section{Special populations}

\section{Children and adolescents}

Danne et $\mathrm{al}^{42}$ compared pharmacokinetic profiles of insulin detemir and NPH across and within different age cohorts, ie, in children and adolescents with type 1 diabetes and using adults as the reference group. They found no significant difference in the area under the curve and maximal serum concentrations of insulin detemir across age groups, and also decreased variability between subjects across and within each age group with detemir versus NPH. In regards to safety, no serious adverse events were reported and no major hypoglycemic episodes were recorded with detemir, and the frequency of minor hypoglycemia was similar to NPH and greater in children in general with both insulins. NPH showed a progressively more rapid absorption with an earlier peak in the younger age groups (children and adolescents), that was not seen with detemir, which increases free insulin levels and thus the risk of hypoglycemia. ${ }^{42}$ This study suggests that detemir is an appropriate basal insulin for use in children and adolescents with the added advantage of less pharmacokinetic variability over NPH, which may help reduce risk of hypoglycemia, and doses may be titrated similarly as is done with adults.

\section{Older adults}

With older adults, of main concern is decreased renal and/or hepatic function, which can result in decreased clearance/ elimination of insulin, leading to hypoglycemia. Higher area under the curve levels were seen with elderly patients using detemir. ${ }^{14}$ Cautious and conservative dosing is recommended for both glargine and detemir.

\section{Ethnic groups}

Patient responses to different pharmaceutical agents may vary across ethnic groups. Hompesch et $\mathrm{al}^{43}$ evaluated the time-action profiles and dose-response relationships of insulin detemir and NPH in type 2 diabetics of different ethnic groups (African American, Hispanic/Latino, and Caucasian). There was a linear dose-response relationship for both detemir and NPH in all three groups. Therefore, similar dosing of detemir can be used in African Americans, Hispanics/Latinos, and Caucasians without the need for different titration algorithms.

\section{Patient-focused perspectives Apprehension about injections}

Glargine and detemir are available in both vial and pen forms. sanofi-aventis produces the Opticlik ${ }^{\mathcal{O}}$ (reusable) and Lantus Solostar ${ }^{\circ}$ (disposable) pens for delivery of glargine, ${ }^{13}$ and Novo Nordisk (Bagsværd, Denmark) produces the NovoPen ${ }^{\circ}$ (reusable) and the FlexPen ${ }^{\circ}$ (disposable) for the delivery of detemir. ${ }^{14}$ Because they are much more portable and easier to use, pens may help to increase patient acceptance, thereby improving satisfaction and adherence to treatment. One advantage over NPH is that both glargine and detemir are suitable for once-daily injection. ${ }^{13,14}$ Adherence to insulin regimens may increase as the complexity of those regimens decrease. Also, glargine and detemir do not require resuspension, providing greater consistency in insulin delivery.

\section{Weight gain}

Weight gain is an undesirable effect of insulin therapy or intensification of insulin therapy. Potential weight gain can be a psychologic barrier to insulin initiation, and actual weight gain can affect tolerance and thus adherence and compliance with ongoing insulin treatment, leading to suboptimal glycemic control. Insulin therapy is associated with a weight gain of $4.0-5.0 \mathrm{~kg}(8.8-11.0 \mathrm{lbs}) .^{44}$ This may be due to decreased glycosuria and overtreatment of hypoglycemia with increased caloric intake. Other possibilities include a role of insulin in lipogenesis and fat deposition and effects of insulin on central nervous system receptors that affect appetite. ${ }^{44}$ Weight gain is not only a cosmetic concern, but may also have an adverse effect on cardiovascular health, through worsening of blood pressure and lipid profiles. ${ }^{44}$

Hermansen and Davies ${ }^{45}$ reviewed the role of insulin detemir in reducing risk of insulin-associated weight gain. Weight gain in people with type 2 diabetes, who are usually already overweight or obese, leads to increased insulin resistance and subsequent increased insulin needs. ${ }^{45}$ Insulin detemir is the only basal insulin shown consistently in randomized, controlled clinical trials to have weight-sparing effects in patients with type 1 and type 2 diabetes. ${ }^{45}$ The weight-sparing effects of insulin detemir appear to be correlated with body mass index (BMI), with the patients having the greatest BMI experiencing the greatest reduction in weight..$^{45}$ The physiologic basis for the weight-sparing effect of detemir is unknown. One hypothesis is that detemir's predictable absorption and action reduce hypoglycemia and reactive overeating. ${ }^{45}$ Another hypothesis is that its albumin-binding properties give it a more physiologic profile in its effects on hepatic and peripheral tissues, to suppress endogenous glucose production and decrease lipogenesis, 
respectively. ${ }^{45}$ Hennige et $\mathrm{al}^{46}$ found that insulin detemir has a tissue-selective action with a preference for the brain over peripheral tissues, likely due to its albumin-binding properties and fatty acid chain that allows it to cross the blood-brain barrier more readily. Because insulin activity on IR receptors has an anorectic effect on mammalian brains under experimental conditions, this suggests a possible mechanism for the weightsparing effects of detemir. ${ }^{46}$

\section{Conclusion}

The improved pharmacokinetic and pharmacodynamic profiles of the basal insulin analogs, glargine and detemir, make them a better choice than NPH for basal insulin replacement. Compared with each other, the ongoing debate is over which insulin has a flatter pharmacodynamic profile and longer duration of action. With the exception of one pharmacodynamic euglycemic clamp study, most studies demonstrate a relatively peakless pharmacodynamic profile for both glargine and detemir and a comparable duration of action that is dose-dependent. Both glargine and detemir are equally effective and suitable for once-daily injection to achieve glycemic control. Safety and efficacy profiles are similar for both, with less hypoglycemia compared with NPH. Insulin glargine has a greater affinity for the human IGF-1 receptor and greater mitogenic potential, compared with human insulin and detemir, but further studies are needed to determine the clinical significance of this.

Patient perspectives that may influence the use of one basal insulin analog over the other include the weight-sparing effect, although modest, of detemir compared with NPH and glargine. Detemir also lasts 42 days once opened, ${ }^{14}$ compared with 28 days for glargine, ${ }^{13}$ so less insulin is wasted at smaller doses. In one study, injection site reactions were more common with detemir.

Glargine and detemir are promising basal insulin analogs, and both have a place in therapy. Provided that safety and efficacy profiles are equal between the two basal insulin analogs, selection of one over the other will most likely come down to patient-focused perspectives such as quality of life, patient satisfaction/acceptability, and adherence.

\section{Acknowledgments}

The authors would like to acknowledge Dawn Clark, MSN, ANP-BC and Gary Wolfe, RN, CCM for their assistance in the critical review of the manuscript.

\section{Disclosure}

Dr Poon reports no conflict of interest in this work. Dr King has been a speaker for and has received research funding from Novo-Nordisk, Lilly, and sanofi-aventis.

\section{References}

1. Wild S, Roglic G, Green A, Sicree R, King H. Global prevalence of diabetes: Estimates for the year 2000 and 2030. Diabetes Care. 2004;27: 1047-1053.

2. World Health Organization. WHO Global Strategy on Diet, Physical Activity, and Health: Diabetes. Available from: http://www.who.int/ dietphysicalactivity/publications/facts/diabetes/en/. Accessed 2010 Feb 28.

3. The Diabetes Control and Complications Trial Research Group. The effect of intensive treatment of diabetes on the development and progression of long-term complications in insulin-dependent diabetes mellitus. N Engl J Med. 1993;329:977-986.

4. Diabetes Control and Complications Trial/Epidemiology of Diabetes Interventions and Complications Research Group: Intensive diabetes treatment and cardiovascular disease in patients with type 1 diabetes. N Engl J Med. 2005;353:2643-2653.

5. Ohkubo Y, Kishikawa H, Araki E, et al. Intensive insulin therapy prevents the progression of diabetes microvascular complications in Japanese patients with NIDDM: A randomized prospective 6-year study. Diabetes Res Clin Pract. 1995;28:103-117.

6. UK Prospective Diabetes Study (UKPDS) Group. Intensive bloodglucose control with sulphonylureas or insulin compared with conventional treatment and risk of complications in patients with type 2 diabetes (UKPDS 33). Lancet. 1998;352:837-853.

7. Holman RR, Paul SK, Bethel MA, et al. 10-year follow-up of intensive glucose control in type 2 diabetes. $N$ Engl J Med. 2008;359: 1577-1589.

8. American Diabetes Association. Standards of medical care in diabetes- 2010 (Position Statement). Diabetes Care. 2010;33 Suppl 1: S11-S61.

9. Nathan DM, Buse JB, Davidson MB, et al. Management of hyperglycemia in type 2 diabetes: A consensus algorithm for the initiation and adjustment of therapy: a consensus statement from the American Diabetes Association and the European Association for the Study of Diabetes. Diabetes Care. 2009;32:193-203.

10. Rodbard HW, Jellinger PS, Davidson JA, et al. Statement by an American Association of Clinical Endocrinologists/American College of Endocrinology consensus panel on type 2 diabetes mellitus: An algorithm for glycemic control. Endocr Pract. 2009;15: 540-559.

11. Lepore M, Pampanelli S, Fanelli C, et al. Pharmacokinetics and pharmacodynamics of subcutaneous injection of long-acting human insulin analogue glargine, NPH insulin, and ultralente human insulin and continuous subcutaneous infusion of insulin lispro. Diabetes. 2000; 49:2142-2148.

12. Heise T, Nosek L, Ronn BB, et al. Lower within-subject variability of insulin detemir in comparison to NPH insulin and insulin glargine in people with type 1 diabetes. Diabetes. 2004;53:1614-1620.

13. sanofi-aventis. Lantus [package insert] Paris, France: sanofi-aventis; 2007.

14. Norvo Nordisk Inc. Detemir [package insert]. Princeton, NJ: Novo Nordisk; 2005.

15. Kurtzhals P. How to achieve a predictable basal insulin? Diabetes Metab. 2005;31:4S25-4S33.

16. Heinnemann L, Linkeschova R, Rave K, et al. Time-action profile of the long-acting insulin analogue insulin glargine (HOE901) in comparison with those of NPH insulin and placebo. Diabetes Care. 2000; 23:644-649.

17. Owens DR, Coates PA, Luzio SD, et al. Pharmacokinetics of 125Ilabeled insulin glargine (HOE 901) in healthy men. Diabetes Care. 2000;23:813-819.

18. Kurtzhals P. Engineering predictability and protraction in a basal insulin analogue: The pharmacology of insulin detemir. Int $J$ Obes. 2004;28:S23-S28.

19. Havelund S, Plum A, Ribel U, et al. The mechanism of protraction of insulin detemir, a long-acting acylated analog of human insulin. Pharm Res. 2004;21:1498-1504. 
20. Dea MK, Hamilton-Wessler M, Ader M, et al. Albumin binding of acylated insulin (NN304) does not deter action to stimulate glucose uptake. Diabetes. 2002;51:762-769.

21. Heise T, Pieber TR. Towards peakless, reproducible and long-acting insulins. An assessment of the basal analogues based on isoglycaemic clamps studies. Diabetes Obes Metab. 2007;9:648-659.

22. HOE 901/1015 Study Investigators Group. Comparison of the timeaction profiles of HOE 901 and human NPH insulin in type 1 diabetic patients using the euglycemic clamp technique. Available from: http://www.accessdata.fda.gov/drugsatfda_docs/nda/2000/21981_ Lantus_biopharmr.pdf. Accessed 2010 Sep 08.

23. Porcellati F, Rossetti P, Busciantella NR, et al. Comparison of pharmacokinetics and dynamics of long-acting insulin analogs glargine and detemir at steady state in type 1 diabetes: A double-blind, randomized, crossover study. Diabetes Care. 2007;30:2447-2452.

24. Plank J, Bodenlenz M, Sinner F, et al. A double-blind, randomized, dose-response study investigating the pharmacodynamic and pharmacokinetic properties of the long-acting insulin analog detemir. Diabetes Care. 2005;28:1107-1112.

25. Klein O, Lynge J, Endahl L, Damolt B, Nosek L, Heise T. Albuminbound basal insulin analogues (insulin detemir and NN344): Comparable time-action profiles but less variability than insulin glargine in type 2 diabetes. Diabetes Obes Metab. 2007;9:290-299.

26. Horvath $\mathrm{K}$, Jeitler K, Berghold A, et al. Long-acting insulin analogues versus NPH (human isophane insulin) for type 2 diabetes mellitus. Cochrane Database Syst Rev. 2007;2:CD005613.

27. Pieber TR, Treichel HC, Hompesch B, et al. Comparison of insulin detemir and insulin glargine in subjects with type 1 diabetes using intensive insulin therapy. Diabet Med. 2007;24:635-642.

28. Rosenstock J, Davies M, Home PD, Larsen J, Koenen C, Schernthaner G A randomized, 52-week, treat-to-target trial comparing insulin detemir with insulin glargine when administered as add-on to glucose-lowering drugs in insulin-naïve people with type 2 diabetes. Diabetologia. 2008; 51:408-416.

29. Hollander P, Cooper J, Bregnhoj J, Pederson CB. A 52-week, multinational, open-label, parallel-group, noninferiority, treat-to-target trial comparing insulin detemir with insulin glargine in a basal-bolus regimen with mealtime insulin aspart in patients with type 2 diabetes. Clin Ther. 2008;30:1976-1987.

30. King AB. No higher dose requirements with insulin detemir than glargine in type 2 diabetes: A cross-over, double-blind, and randomized study using continuous glucose monitoring. J Diabetes Sci Technol. 2010;4:151-154.

31. Dornhorst A, Luddeke HJ, Sreenan S, et al. Safety and efficacy of insulin detemir in clinical practice: 14 week follow-up data from type 1 and type 2 diabetes patients in the PREDICTIVE European cohort. Int $J$ Clin Pract. 2007;61:523-528.

32. Dornhorst A, Luddeke HJ, Koenen C, et al. Transferring to insulin detemir from NPH insulin or insulin glargine in type 2 diabetes patients on basal-only therapy with oral anitdiabetic drugs improves glycaemic control and reduces weight gain and risk of hypoglycemia: 14-week follow-up data from PREDICTIVE. Diabetes Obes Metab. 2008; 10:75-81.
33. Meneghini LF, Rosenberg KH, Koenen C, Merilainen MJ, Luddeke HJ. Insulin detemir improves glycaemic control with less hypoglycemia and no weight gain in patients with type 2 diabetes who were insulin naïve or treated with NPH or insulin glargine: Clinical practice experience from a German subgroup of the PREDICTIVE study. Diabetes Obes Metab. 2007;9:418-427.

34. Yenigun M, Honka M. Switching patients from insulin glargine-based basal-bolus regimens to a once daily insulin detemir-based basal-bolus regimen: Results from a subgroup of the PREDICTIVE study. Int J Clin Pract. 2009;63:425-432.

35. Cryer P, editor. Hypoglycemia in Diabetes: Pathophysiology, Prevalence, and Prevention. Alexandria, VA: American Diabetes Association; 2009.

36. Riddle MC, Rosenstock J, Gerich J, et al. The treat-to-target trial: Randomized addition of glargine or human NPH insulin to oral therapy of type 2 diabetic patients. Diabetes Care. 2003;26:3080-3086.

37. Kurtzhals P, Schaffer L, Sorensen A, et al. Correlations of receptor binding and metabolic and mitogenic potencies of insulin analogs designed for clinical use. Diabetes. 2000;49:999-1005.

38. Hemkins LG, Grouven U, Bender R, et al. Risk of malignancies in patients with diabetes treated with human insulin or insulin analogues: A cohort study. Diabetologia. 2009;52:1732-1744.

39. Ehninger G, Schmidt AH. Putting insulin glargine and malignancies into perspective. Oncologist. 2009;14:1169-1174.

40. Giovannucci E, Harlan DM, Archer MC, et al. Diabetes and Cancer: A consensus report. Diabetes Care. 2010;33:1674-1685.

41. Pollex EK, Feig DS, Lubetsky A, Yip PM, Koren G. Insulin glargine safety in pregnancy: A transplacental transfer study. Diabetes Care. 2010;33:29-33.

42. Danne T, Lupke K, Walte K, et al. Insulin detemir is characterized by a consistent pharmacokinetic profile across age-groups in children, adolescents, and adults with type 1 diabetes. Diabetes Care. 2003;26: 3087-3092.

43. Hompesch M, Troupin B, Heise T, et al. Time-action profile of insulin detemir and NPH insulin in patients with type 2 diabetes from different ethnic groups. Diabetes Obes Metab. 2006;8:568-573.

44. Hollander P. Anti-diabetes and anti-obesity medications: Effects on weight in people with diabetes. Diabetes Spectr. 2007;20:159-165.

45. Hermansen K, Davies M. Does insulin detemir have a role in reducing risk of insulin-associated weight gain? Diabetes Obes Metab. 2007;9:209-217.

46. Hennige AM, Sartorius T, Tschritter O, et al. Tissue selectivity of insulin detemir action in vivo. Diabetologia. 2006;49:1274-1282.
Drug, Healthcare and Patient Safety

\section{Publish your work in this journal}

Drug, Healthcare and Patient Safety is an international, peer-reviewed open-access journal exploring patient safety issues in the healthcare continuum from diagnostic and screening interventions through to treatment, drug therapy and surgery. The journal is characterized by the rapid reporting of reviews, original research, clinical, epidemiological and

\section{Dovepress}

post-marketing surveillance studies, risk management, health literacy and educational programs across all areas of healthcare delivery. The manuscript management system is completely online and includes a very quick and fair peer-review system. Visit http://www.dovepress.com/ testimonials.php to read real quotes from published authors. 